\title{
Hereditary spherocytosis and human immunodeficiency virus (HIV) infection: is there an association?
}

\author{
Faheem Seedat ${ }^{1,2}$, Moosa Patel $^{3 *}$, Faadil Waja ${ }^{3}$, Farai Sigauke ${ }^{1,2}$ and Ebrahim Variava ${ }^{1,2}$ \\ *Correspondence: moosa.patel@wits.ac.za

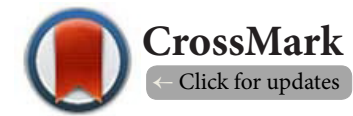 \\ 'Department of Internal Medicine, Klerksdorp/Tshepong Hospital Complex, North West Department of Health, Klerksdorp, \\ South Africa. \\ 2Department of Internal Medicine, Faculty of Health Sciences, University of Witwatersrand, Johannesburg, South Africa. \\ ${ }^{3}$ Department of Internal Medicine, Chris Hani Baragwanath Academic Hospitalc and Faculty of Health Sciences, \\ University of Witwatersrand, Johannesburg, South Africa.
}

\begin{abstract}
Hereditary Spherocytosis (HS) is a hereditary red cell membrane cytoskeleton abnormality that results in a chronic haemolytic anaemia. We report on a 26-year-old Human immunodeficiency virus (HIV) seropositive woman who presented with HS. Red cell membrane studies confirmed the diagnosis in the patient and her 6 year old son. The association between HS and HIV is likely to be coincidental. However, the symptoms and signs of HS may be modified (often exaggerated) in the presence of HIV.
\end{abstract}

Keywords: Hereditary spherocytosis (HS), hereditary, chronic haemolytic anaemia, human immunodeficiency virus (HIV), red cell membrane

\section{Introduction}

Hereditary Spherocytosis (HS) is an inherited disorder of the red cell membrane, due to defects in the proteins of the red cell cytoskeleton [1]. These defects cause red cell membrane instability and loss resulting in the characteristic spherocytic shaped cells, which are trapped and destroyed in the spleen [2]. $\mathrm{HS}$ is more common in European Caucasians and is considered rare in those of African ancestry [3]. HS presents with features of a chronic haemolytic anaemia: anaemia, jaundice, splenomegaly, gallstones and leg ulcers. A family history may or may not be present. The age and severity of clinical presentation is variable $[\mathbf{1 , 2}, \mathbf{4}]$. Diagnostic testing includes a three-armed approach: establishing the presence of hemolysis, confirming the presence of spherocytes and determining the specific protein defect through sodium dodecyl sulphate-polyacrylamide gel electrophoresis $[\mathbf{1}, \mathbf{2}, \mathbf{4}]$. The treatment modality of choice in those with moderate to severe forms of disease is splenectomyto ameliorate the destructive effect of the spleen on the spherocytic red cells. Splenectomy reduces the degree of haemolysis and subsequent complications. However, the risks of post-splenectomy infection must be considered and managed prior to and after surgery $[\mathbf{1 , 2}, \mathbf{4}]$. We consider the associations and impact HIV co-infection may have on the clinical presentation and treatment in patients with HS.

\section{Case presentation}

A 26-year-old female of African ethnicity from the township of
Khuma, in the North West Province of South Africa, presented with yellow discolouration of her eyes, pallor, dizziness and generally feeling unwell. She admitted to a history of previous hospitalisations as a child, were she had received multiple blood transfusions. She was diagnosed as being HIV seropositive at her local clinic 5 years ago, with a CD4 count 173 cells/ul, and was not on antiretroviral therapy. She had a 6 -year-old son who had yellow discolouration of his eyes at times but at no stage required a blood transfusion. He was confirmed to be HIV seronegative. Furthermore, she reported that her father had received blood transfusions previously but could not recall further details. She reported no history of medical illnesses experienced by her mother.

On examination, the patient was jaundiced and had conjunctival pallor. She had no clinical features of chronic liver disease or a bleeding tendency. Hepatosplenomegaly was noted on abdominal examination: the liver was palpable $8 \mathrm{~cm}$ below the right costal margin in the mid-clavicular line, with a total span of $18 \mathrm{~cm}$, and the spleen was palpable $8 \mathrm{~cm}$ below the left costal margin. No ascites was present. There were no leg ulcers and examination of her other systems were normal.

Her initial full blood count (FBC) demonstrated a normocytic normochromic anaemia with a haemoglobin of $6.3 \mathrm{~g} / \mathrm{dl}$ (see Table 1). Her Reticulocyte Production Index (RPI) was 0.8 with a normal LDH of $233 \mathrm{U} /$. Liver function tests showed an unconjugated hyperbilirubinemia of $36 \mathrm{umol} / \mathrm{l}$. Follow up of FBC analysis demonstrated the persistence of the normocytic

() 2015 Patel et al; licensee Herbert Publications Ltd. This is an Open Access article distributed under the terms of Creative Commons Attribution License (http://creativecommons.org/licenses/by/3.0). This permits unrestricted use, distribution, and reproduction in any medium, provided the original work is properly cited. 
Seedat et al. Hematology and Leukemia 2015,

normochromic anaemia with subsequent elevated RPI values of 3.5 and 2.2 respectively (see Table 1 ). Her red cell folate, vitamin B12 and ferritin levels were normal. The peripheral blood smear demonstrated moderate anisocytosis with a dimorphic red blood cell picture and spherocytes. Her Coombs test was negative.

Radiological investigations (abdominal sonar and CAT computerised axial tomographic scan) confirmed the hepatosplenomegaly with patent portal and splenic veins. A $13 \mathrm{~mm} \times 11 \mathrm{~mm}$ calculus was also noted in the gallbladder.

Bone marrow examination showed a hypercellur bone marrow and no evidence of primary bone marrow pathology.

A diagnosis of HS was considered and confirmed on red cell membrane studies with sodium dodecyl sulphatepolyacrylamide gel electrophoresis (SDS-PAGE). This was also performed on the son and father (see Table 2).

In the patient and her son SDS-PAGE confirmed a decreased protein 4.2 content, a decreased protein $4.1 \mathrm{a} / \mathrm{b}$ ratio and a slower mobility of band 3. The SDS-PAGE on the father revealed a slower mobility of band 3 but no other abnormalities.

The diagnosis of HS was confirmed in our patient and her son. Both were started on folate supplementation. The patient was initiated on combination antiretroviral therapy as per South African guidelines and received a transfusion of packed red cells. Due to the severity of her disease she was offered

Table 1. Relevant blood investigations.

\begin{tabular}{llll}
\hline Investigations & Initial & Two months later & One year later \\
\hline WCC $\left(\times 10^{9} / \mathrm{l}\right)$ & 20.7 & 4.95 & 2.61 \\
$\mathrm{HB}(\mathrm{g} / \mathrm{dl})$ & 6.3 & 6.4 & 5.4 \\
$\mathrm{MCV}(\mathrm{fl})$ & 83.1 & 91 & 87.2 \\
Platelet count $(\mathrm{x} \mathrm{10} / \mathrm{l})$ & 152 & 159 & 161 \\
RPI & 0.8 & 3.5 & 2.2 \\
LDH (U/l) & 311 & 233 & -- \\
\hline
\end{tabular}

an elective splenectomy together with a cholecystectomy. However, she refused to have any surgical intervention. A repeat full blood count a year later still showed a normocytic anaemia, with a haemoglobin of $5.4 \mathrm{~g} / \mathrm{dl}$, with an elevated RPI of 2.2 confirming ongoing hemolysis.

At her latest follow up (approximately 1 year and 9 months after her diagnosis of HS), she had a haemoglobin of $7.2 \mathrm{~g} /$ $\mathrm{dl}$, with an RPI of 4.2. Her CD4 count has increased from 173 cells/ul to 324 cells/ul. However, her viral load has also increased from 15721 RNA copies/ml to 101503 RNA copies/ $\mathrm{ml}$, suggesting poor compliance to her antiretroviral therapy (which she has admitted to).

The ongoing anaemia is likely to be a contribution from both HS and HIV, although the high RPI would favour a dominant contribution from HS. As such, she has been counselled regarding her compliance and the possibility of a splenectomy, once her response to antiretroviral therapy has been optimised, should she have evidence of ongoing moderate to severe HS.

\section{Discussion and conclusion}

Hereditary Spherocytosis (HS) is an inherited haemolytic anaemia most common in Caucasian individuals of European ancestry with a prevalence of 1:2000-1:5000 [3]. Although uncommon in Africa, the entity has been described in the South African population: more in communities of Mediterranean heritage but also noted in patients of African ancestry $[5,6]$. HS is due to a genetic abnormality: usually inherited in an autosomal dominant fashion (75\%), though, recessive inheritance (25\%) and de novo mutations do occur [3].

The phenotypic severity of HS, related to the degree of hemolysis, is variable and comprises: mild, moderate or severe disease $[\mathbf{1 , 2 , 4 ]}$. With worsening severity, the splenomegaly is more prominent, the haemoglobin level is lower and the reticulocyte count and bilirubin levels are higher, together with a greater need for blood transfusion.

Table 2. Summary of investigations performed on the patient and her family.

\begin{tabular}{|c|c|c|c|}
\hline Investigations & Patient & Son & Father \\
\hline Haemoglobin $(\mathrm{g} / \mathrm{dl})$ & 6.4 & 10.7 & 14.9 \\
\hline $\operatorname{MCV}(\mathrm{fl})$ & 87.6 & 74.6 & 88.4 \\
\hline $\begin{array}{l}\text { Peripheral blood } \\
\text { smear }\end{array}$ & $\begin{array}{l}\text { Moderate } \\
\text { anisocytosis; } \\
\text { dimorphic red cells; } \\
\text { spherocytes }\end{array}$ & $\begin{array}{l}\text { Mild microcytosis; } \\
\text { spherocytes }\end{array}$ & Normal \\
\hline RPI & 3.5 & 1.5 & 0.8 \\
\hline $\mathrm{LDH}(\mathrm{U} / \mathrm{l})$ & 311 & 344 & 154 \\
\hline Coombs test & Negative & Negative & Negative \\
\hline Radiological & $\begin{array}{l}\text { Liver-18cm; } \\
\text { spleen-18cm; } \\
\text { gallstone present }\end{array}$ & $\begin{array}{l}\text { Liver-10.9cm; } \\
\text { spleen- } 8.2 \mathrm{~cm} \text {; no } \\
\text { gallstones }\end{array}$ & Not performed \\
\hline SDS-page & Protein 4.2 deficiency & Protein 4.2 deficiency & Normal \\
\hline
\end{tabular}


Seedat et al. Hematology and Leukemia 2015,

http://www.hoajonline.com/journals/pdf/2052-434X-3-3.pdf

doi: 10.7243/2052-434X-3-3

The treatment of HS involves supportive measures such as folate supplementation and blood transfusions for symptomatic anaemia [1], and specific modalities including splenectomy for moderate to severe disease. Importantly, post -splenectomy infection risk must be managed. Prior to surgery patients should be counselled and receive immunisations against S.pneumoniae, H.influenzae type b and Neisseira Meningitidis, and the need for re-immunization and postsplenectomy antibiotic prophylaxis should be considered based on local management protocols $[1,2,4]$. In children under the age of 6 , surgery should be delayed until 6-9 years due to the increased infection risk of post-splenectomy $[\mathbf{1 , 2 , 4 ]}$.

No published data could be found regarding the association between HS and HIV co-infection. HS is due to a specific genetic defect and no causal relationship exists between HIV and HS [3]. However, HS in the setting of a patient with HIV poses challenges and important questions. HIV is a well recognised cause of bone marrow suppression [7], and the anaemia associated with $\mathrm{HS}$, together with HIV co-infection may not follow the typical course: the anaemia may be more severe and the reticulocyte count or reticulocyte production index may be lower than expected due to a poor bone marrow response to haemolysis. As a result of this, the haemolysis may be masked as was evident in our patient initially. Additionally, Parvovirus B19 is more common in patients with HIV [8]. Parvovirus B19 can result in a pure red cell aplasia and in the presence of a chronic haemolytic state such as HS, an aplastic crisis may be precipitated. Furthermore, HIV is associated with autoimmune haemolytic anaemia (AIHA) [9], which like HS, presents with hemolysis and spherocytes on the peripheral blood smear, but unlike HS, the Coombs test is positive in AlHA.

HIV co-infection may also result in patients presenting with a larger splenomegaly than expected [10]. This may result in overestimating the severity of the disease. Moreover, splenectomy in patients with HIV must be carefully considered. Patients with HS and HIV co-infection, due to the added immune compromise, are generally expected to have a greater risk of infection post splenectomy. Importantly, the need for post-splenectomy infection prophylaxis and earlier initiation of antiretroviral therapy may be required. Furthermore, absolute CD4 counts are noted to rise post splenectomy and whether these values can be used to make decisions regarding initiation of antiretroviral therapy or prophylaxis against opportunistic infections must be considered. Currently, it is recommended that the CD4 cell percentage and HIV viral loads should be used instead of the absolute CD4 counts in such a situation [11].

Human immunodeficiency virus (HIV) infection is endemic in South Africa. It is estimated that in 2012, $12.2 \%$ of the population (6.4 million persons) were HIV seropositive, based on a National HIV survey [12]. The vast majority of individuals acquire HIV through heterosexual contact. Blood transfusion is a very rare cause of HIV transmission in South Africa. This is directly attributable to the availability of safe blood. The HIV prevalence is estimated at $0.46 \%$ among first-time blood donors and $0.03 \%$ among regular blood donors [13]. As such, it is highly unlikely that our patient acquired her HIV through contaminated blood. This is similar to a report from Thailand, where none of the haematology patients who received multiple blood transfusions (including 1 patient with HS) were found to be seropositive, despite the possibility of HIV being transmitted in contaminated blood in the window period, with an estimated HIV antigen positivity of 1:10 000 in Thailand [14].

Although HIV and HS have no causal association, HIV complicating HS has important implications on the clinical presentation and therapeutic options. This poses additional challenges and the clinician needs to be aware of this, particularly in areas of high HIV seroprevalence, where this rare association may occasionally be encountered.

\section{Competing interests}

The authors declare that they have no competing interests.

Authors' contributions

\begin{tabular}{|l|c|c|c|c|c|}
\hline Authors' contributions & FS1 & MP & FW & FS2 & EV \\
\hline Research concept and design & $\checkmark$ & $\checkmark$ & $\checkmark$ & $\checkmark$ & $\checkmark$ \\
\hline Collection and/or assembly of data & $\checkmark$ & $\checkmark$ & $\checkmark$ & $\checkmark$ & $\checkmark$ \\
\hline Data analysis and interpretation & $\checkmark$ & $\checkmark$ & -- & -- & $\checkmark$ \\
\hline Writing the article & $\checkmark$ & $\checkmark$ & -- & -- & -- \\
\hline Critical revision of the article & $\checkmark$ & $\checkmark$ & -- & -- & -- \\
\hline Final approval of article & $\checkmark$ & $\checkmark$ & $\checkmark$ & $\checkmark$ & $\checkmark$ \\
\hline Statistical analysis & -- & -- & -- & -- & -- \\
\hline
\end{tabular}

\section{Acknowledgement}

The patient and her family; the staff of the Internal Medicine Department at Klerksdorp/Tshepong Hospital Complex; and the Red Cell Membrane unit, National Health Laboratory Service (NHLS), University of Witwatersrand, Johannesburg, South Africa.

\section{Publication history}

EIC: Evangelos Terpos, University of Athens School of Medicine, Greece.

Received: 15-Apr-2015 Final Revised: 21-Jun-2015

Accepted: 07-Jul-2015 Published: 16-Jul-2015

\section{References}

1. Bolton-Maggs PH, Langer JC, Iolascon A, Tittensor P and King MJ. Guidelines for the diagnosis and management of hereditary spherocytosis--2011 update. Br J Haematol. 2012; 156:37-49. | Article | PubMed

2. Perrotta S, Gallagher PG and Mohandas N. Hereditary spherocytosis. Lancet. 2008; 372:1411-26. | Article | PubMed

3. Mariani M, Barcellini W, Vercellati C, Marcello AP, Fermo E, Pedotti P, Boschetti $C$ and Zanella A. Clinical and hematologic features of $\mathbf{3 0 0}$ patients affected by hereditary spherocytosis grouped according to the type of the membrane protein defect. Haematologica. 2008; 93:1310-7. | Article | PubMed

4. Da Costa L, Galimand J, Fenneteau O and Mohandas N. Hereditary spherocytosis, elliptocytosis, and other red cell membrane disorders. Blood Rev. 2013; 27:167-78. | Article | PubMed

5. Bonafede RP, Botha MC and Beighton P. Inherited anaemias in the Greek community of Cape Town. J Med Genet. 1979; 16:197-200. | Article | PubMed Abstract | PubMed Full Text 
Seedat et al. Hematology and Leukemia 2015,

http://www.hoajonline.com/journals/pdf/2052-434X-3-3.pdf

6. Spector I and Metz J. A Bantu family with hereditary spherocytosis. S Afr Med J. 1963; 37:211-3. | PubMed

7. Redig AJ and Berliner N. Pathogenesis and clinical implications of HIVrelated anemia in 2013. Hematology Am Soc Hematol Educ Program. 2013; 2013:377-81. | Article | PubMed

8. Koduri PR. Parvovirus B19-related anemia in HIV-infected patients. AIDS Patient Care STDS. 2000; 14:7-11. | Article | PubMed

9. Saif MW. HIV-associated autoimmune hemolytic anemia: an update. AIDS Patient Care STDS. 2001; 15:217-24. | Article | PubMed

10. Furrer $\mathrm{H}$. Prevalence and clinical significance of splenomegaly in asymptomatic human immunodeficiency virus type 1-infected adults. Swiss HIV cohort study. Clin Infect Dis. 2000; 30:943-5. | Article | PubMed

11. Molina J-M. Surrogate Markers Following Splenectomy in HIV-Infected Patients? Medscape HIV/AIDS. 2001; 7.

12. Shisana O, Stoker D, Simbayi LC, Orkin M, Bezuidenhout F, Jooste SE, Colvin $M$ and van Zyl J. South African national household survey of HIV/ AIDS prevalence, behavioural risks and mass media impact--detailed methodology and response rate results. S Afr Med J. 2004; 94:283-8. | Pdf | PubMed

13. Dhingra N. Making safe blood available in Africa. Coordinator, Blood Transfusion Safety, World Health Organization (WHO). 2006. I Pdf

14. Mahaphan $W$, Hathirat $P$, Isarangkura $P$, Chuansumrit $A$, Atnaseo $P$, Panthangkura W and Chiewsilp P. HIV seroprevalence in hematologic patients other than hemophiliacs at Ramathibodi Hospital. Southeast Asian J Trop Med Public Health. 1993; 24 Suppl 1:187-90. I PubMed

\section{Citation:}

Seedat F, Patel M, Waja F, Sigauke F and Variava E. Hereditary spherocytosis and human immunodeficiency virus (HIV) infection: is there an association? Hematol Leuk. 2015; 3:3. http://dx.doi.org/10.7243/2052-434X-3-3 